\title{
Numerical modelling of a bubbling fluidized bed combustor
}

\author{
S. Ravelli \& A. Perdichizzi \\ Department of Industrial Engineering, Bergamo University, Italy
}

\begin{abstract}
A numerical model of a bubbling fluidized bed combustor fed by refuse derived fuel is presented. The combustor is divided into two regions: the bed and the freeboard. The calculation of mass and energy fluxes entering from the bed into the freeboard provides the boundary conditions for the subsequent CFD analysis. The three-dimensional freeboard model, implemented by means of the commercial code FLUENT 6.1, is mainly concerned with employing the twomixture-fraction-pdf approach to track both the flue gas coming from the bed and the solid fuel particles that do not burn in the bed, but above it. The excess air is injected through four series of nozzles; the heat exchange between the combustion gases and the boiler tubes is also taken into account in the model. The comparison between the predicted and the experimental data shows a good agreement about chemical species concentrations, velocity and temperature profiles along the freeboard height. The reliability of the simulation results proves that CFD modelling is a valid instrument to analyse the behaviour of non conventional furnaces.
\end{abstract}

Keywords: CFD modelling, fluidized bed combustion, freeboard, refuse derived fuel.

\section{Introduction}

The fluidized bed combustor (FBC) is a flexible and reliable technology that carries out combustion at lower operating temperatures $\left(700-950^{\circ} \mathrm{C}\right)$ in comparison with conventional boilers. So, it's possible to reduce considerably the pollutants emitted with the flue gas; besides, limestone or dolomite can be brought into the bed to adsorb sulphur and halogen compounds. Carbon monoxide and unburned hydrocarbon discharged in atmosphere are very low 
since fluidization guarantees high combustion efficiency and high gas-solid mixing. These features make the FBC suitable not only for coal but also for alternative fuels, such as RDF or biomass.

Investigations on solid fuel combustion have been carried out not only with one-dimensional but also with multi-dimensional models: the former has been diffusely employed in chemically reactive fluidized bed simulation (Sriramulu et al. [1], Marias et al. [2], Scala and Salatino [3]); the latter is currently being applied only to conventional combustion processes (Stopford [4], Eastwick et al [5], Eaton et al. [6]). Attention has been drawn to multi-dimensional numerical models focused on the combustor simulation. While once confined to specialized researches, these models are gradually becoming more accessible as features in commercially available CFD codes. Time requirement for their running is also becoming much more acceptable due to improved numerical methods and advanced hardware technology. These positive circumstances has made the three-dimensional, comprehensive model of a real furnace an attainable goal. The present investigation is limited to the CFD analysis of the freeboard since numerical method can't deal with the 3D modelling of reactive fluidized beds at the moment. As a consequence, the bed behaviour has been estimated by means of simple mass and energy balances that provide the boundary conditions for the freeboard model. This has been implemented by FLUENT version 6.1 [7]. Continuity, momentum, turbulence, energy and mixture fraction equations are solved sequentially in an iterative way until the converged criteria are satisfied. Predictions have been validated against a set of experimental data measured by the FBC monitoring system. The great potential offered by CFD stands out in the post-processing: qualitative and quantitative information about the flow field can be easily obtained throughout the whole domain.

\section{The bubbling FBC}

The present investigation has been carried out for the furnace of the waste-toenergy plant owned by BAS-ASM, a municipal utility operating in North Italy. The FBC (fig.1) is fed by RDF by means of fluff or pellets. Two stokers throw the solid particles into the combustor; their trajectory varies according to their shape and their weight: the heaviest ones quickly fall in the bed while the finest ones are carried by the gas phase throughout the freeboard.

In the bed, the RDF particles burn thanks to the primary air, which is injected through the bottom of the furnace by means of tuyeres, and provide the necessary heat to keep the bed temperature constant $\left(750-800^{\circ} \mathrm{C}\right)$. In the freeboard, the fine particles are yielded to combustion by the secondary air, injected on two different levels.

The boiler tubes, completely embedded in the furnace, are vertically set: they are held together in 4 bundles and each bundle is composed of 11 tubes. In the bottom part, approaching the bed, they assume an "U"; the horizontal lines of the "U" are sloped of $10^{\circ}$ in order to promote water circulation. 


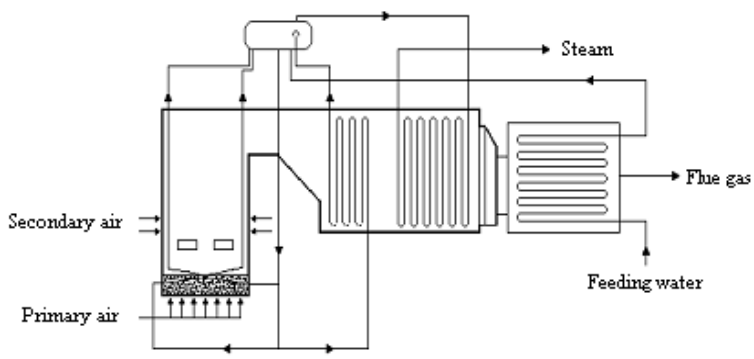

Figure 1: Schematic diagram of the FBC, part of the heat recovery steam generator.

\section{Mass and energy balances in the fluidized bed}

Since it is impracticable to measure the fraction of fuel that falls into the bed, an hypothesis has been made according to which a percentage varying from $60 \%$ to $75 \%$ of the fuel fed to furnace burns in the bed. This percentage is related to the temperature of the bed, that is supposed to be isothermal.

The ultimate and proximate analysis of the RDF are shown in table 1 . The assumption about the complete conversion of the fuel fixed carbon to $\mathrm{CO}_{2}$ allows to compute the flue gas flow rate and composition, in terms of $\mathrm{CO}_{2}, \mathrm{H}_{2} \mathrm{O}, \mathrm{N}_{2}$ and $\mathrm{O}_{2}$. The bed temperature, resulting from the energy balance, increases consistently to the fuel percentage burning in the bed (fig. 2). The combustion heat is partly taken out by the boiler tubes located inside the bed $(33 \%)$ and partly carried by the combustion gases entering the freeboard $(66 \%)$. Since the case in which $60 \%$ of the RDF burns in the bed describes the most recurrent combustor configuration, it has been selected as the reference for the subsequent freeboard modelling.

Table 1: RDF data.

\begin{tabular}{|c|c|c|c|}
\hline \multicolumn{2}{|c|}{$\begin{array}{c}\text { Ultimate } \\
\text { analysis (\%wt) }\end{array}$} & $\begin{array}{c}\text { Proximate analysis } \\
(\% \mathrm{wt})\end{array}$ \\
\hline $\mathrm{C}$ & 51.244 & Moisture & 8 \\
$\mathrm{H}$ & 4.232 & Fixed C & 3.9 \\
$\mathrm{~N}$ & 0.644 & Volatiles & 75.6 \\
$\mathrm{O}$ & 16.376 & Ash & 12.5 \\
\cline { 3 - 4 } $\mathrm{S}$ & 0.46 & LHV $(\mathrm{kJ} / \mathrm{kg})$ & 19374 \\
\hline
\end{tabular}

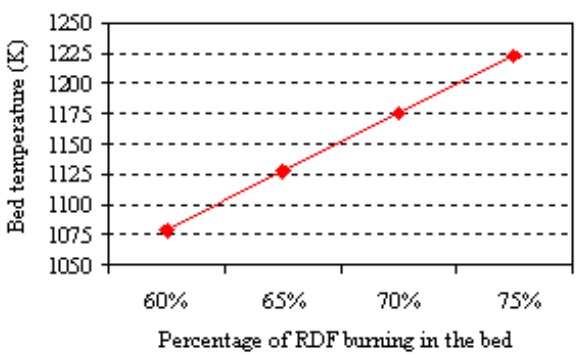

Figure 2: Bed temperature as a function of the RDF percentage burning in the bed. 


\section{Freeboard modelling}

\subsection{The grid}

The three-dimensional model represents accurately the full scale freeboard with its internals (fig. 3). From the base $(4.58 \mathrm{~m}$ by $5.928 \mathrm{~m}$ ) the flue gas enters the freeboard; the secondary air is injected into the furnace through four series of nozzles, whose diameter is $0.051 \mathrm{~m}$. Each series is composed of 12 nozzles. The distance between the base and the two secondary air injection planes is $2.96 \mathrm{~m}$ and $3.96 \mathrm{~m}$, respectively. The freeboard is $12.36 \mathrm{~m}$ high and is fed by two RDF entry ports $(0.9 \mathrm{~m}$ by $0.2 \mathrm{~m})$ equally spaced on the front. The combustion products, before leaving the freeboard through the side exit $(5.928 \mathrm{~m}$ by $1.6 \mathrm{~m})$, transfer heat to 44 evaporative tubes. Their diameter is not constant: it equals $0.076 \mathrm{~m}$ at the tube bend and it decreases to $0.064 \mathrm{~m}$ at the straight stretch. The diameter reduction along the freeboard height favours the natural circulation of the two-phase fluid flowing in the tubes.

An unstructured grid of 5.344.716 cells has been applied to the freeboard volume; the resultant total number of nodes is 1.111 .183 . The desire to thicken the mesh just to achieve high calculation accuracy faced up with the need to limit computation time. Consequently, the mesh had to be thickened only in the critical regions. Since heat transfer modelling may be severely affected by grid features, the highest concentration of cells has been restricted to the areas close to the boiler tubes.

\subsection{The numerical model}

The framework of the CFD model, composed of equations for conservation of mass, energy and momentum combines sub-models accounting for gaseous species mixing and chemical reactions, fuel particles devolatilization and char oxidation. The temperature field is mainly governed by radiant energy transport as well as the heat exchange between the combustion gases and the boiler tubes. The incompressible steady state form of the conservation equations was solved with the segregated SIMPLE-based approach. Additional transport equations for the turbulent kinetic energy $\mathrm{k}$ and its dissipation rate $\varepsilon$ were considered: the realizable $\mathrm{k}-\varepsilon$ model was chosen for modelling the turbulence. The solid fuel combustion has been modelled using the two-mixture fraction-pdf formulation. In this approach, the reacting system can include three streams at most:

- one "fuel", i.e. the RDF flow rate that doesn't burn in the bed;

- one "secondary stream", i.e. the flue gas coming from the bed;

- one "oxidiser", i.e. the secondary air.

Transport equations for conserved scalars quantities, the mixture fractions, are solved instead of the individual species transport equations. The mixture fractions are simply the mass fractions of each stream, therefore the sum of all three mixture fractions is always equal to 1 . Species mole fractions and other instantaneous fluid properties, such as density and temperature, derive from the predicted mixture fractions distribution. 


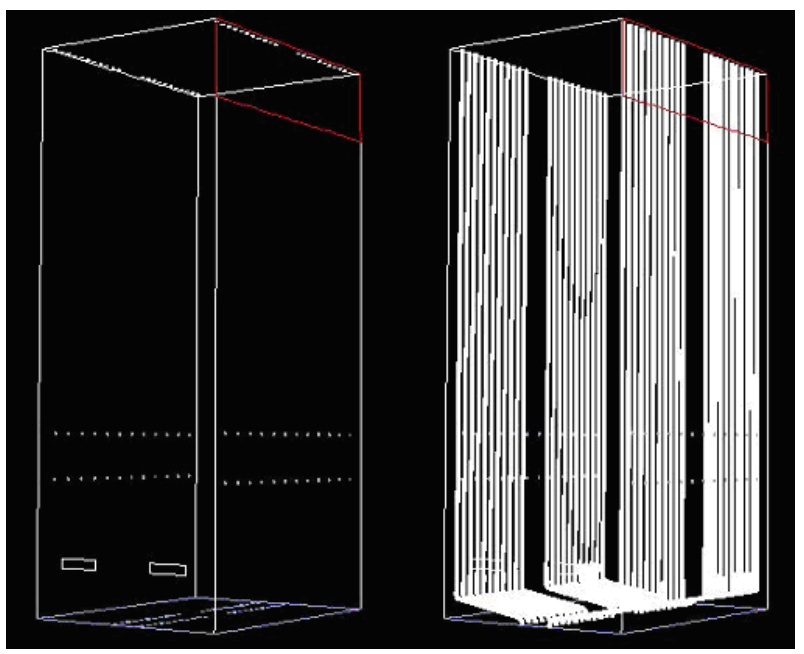

Figure 3: Three-dimensional freeboard model with its internals. The mass flow inlet faces are coloured blue; the outlet face is coloured red; the wall faces are coloured white.

The reaction system is computed according to the infinite rate chemistry: mole fraction of every species is predicted in accordance with the chemical equilibrium. The species included in the model were the following: $\mathrm{C}_{3} \mathrm{H}_{8}, \mathrm{CO}$, $\mathrm{CO}_{2}, \mathrm{H}_{2} \mathrm{O}(\mathrm{L}), \mathrm{H}_{2} \mathrm{O}, \mathrm{H}_{2}, \mathrm{~N}_{2}, \mathrm{C}(\mathrm{S}), \mathrm{O}_{2}, \mathrm{C}, \mathrm{H}, \mathrm{N}, \mathrm{O}$, according to the kinetic models of solid organic fuels combustion (Boiko and Pachkovskii [8]).

The RDF particles were tracked in a Lagrangian frame of reference by the discrete phase model. The impact of the discrete phase on the continuous phase is accounted by the inter-phase exchange of momentum, heat and mass transfer: all these terms derive from the sub-models describing the combustion process, such as heating, devolatilization and char burnout.

Since the optical thickness is greater than unity, the P1 model has been considered the most suitable to simulate the radiative energy transport. Although it's easy to solve with little CPU demand, it accounts for scattering and radiation exchange between gas and fuel particles. The gas absorption coefficient was set to be a function of local concentration of water vapour and carbon dioxide whereas fuel particles were characterized by constant emission and scattering coefficients.

\subsection{Input data and boundary conditions}

The fuel features were defined through a series of chemical and physical properties (table 2), including not only the composition but also the particles shape and size. The cumulative size distribution of the RDF particles burning in the freeboard is shown in fig. 4. The subsequent step towards the complete model was the definition of the boundary conditions (table 3 ): the flue gas entering the freeboard from its base and the secondary air injection through the 
nozzles were modelled by the "mass flow inlet" condition; the freeboard exit was specified by the "pressure outlet" condition; finally, the condition of "wall" was applied to the freeboard walls and the boiler tubes, whose temperature was supposed to be constant and equal to $1175 \mathrm{~K}$ and $600 \mathrm{~K}$, respectively.

The turbulence boundary condition was indicated as turbulence intensity: $10 \%$ is enough to represent fully developed turbulence. The gauge pressure is zero: it means that the freeboard pressure was assumed to be constant and equal to the atmospheric pressure. The boundary conditions required by the discrete phase model (DPM) on each surface determine the fuel particle trajectory on the physical boundary. The available conditions are the following: "trap" means that the trajectory calculation terminates and the remaining volatile mass is passed into the vapour phase; "escape" denotes that the trajectory calculation is terminated; "reflect" signifies that the particle is rebounded off the boundary. The first condition was applied to the freeboard base, as the fuel particles falling on this surface volatilise.

Table 2: $\quad$ RDF data.

\begin{tabular}{|l|c|}
\hline Density $\left(\mathrm{kg} / \mathrm{m}^{3}\right)$ & 1230 \\
\hline Specific heat $(\mathrm{J} / \mathrm{kgK})$ & 1000 \\
\hline $\begin{array}{l}\text { Thermal conductivity } \\
(\mathrm{W} / \mathrm{mK})\end{array}$ & 0.0454 \\
\hline $\begin{array}{l}\text { Devolatilization } \\
\text { temperature }(\mathrm{K})\end{array}$ & 400 \\
\hline Binary diffusivity $\left(\mathrm{m}^{2} / \mathrm{s}\right)$ & 0.0005 \\
\hline Swelling coefficient & 2 \\
\hline Emissivity & 0.8 \\
\hline Scattering factor & 0.6 \\
\hline
\end{tabular}

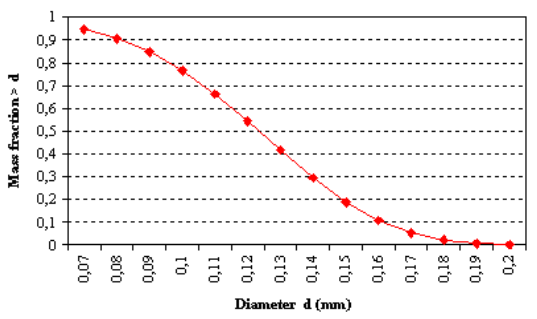

Figure 4: Cumulative size distribution of RDF particles burning in the freeboard.

Table 3: $\quad$ CFD freeboard model boundary conditions.

\begin{tabular}{|l|l|l|l|}
\hline Surface & Boundary Condition & \multicolumn{2}{|c|}{ Input } \\
\hline Freeboard base & Mass flow inlet & $\begin{array}{l}\mathrm{T}=1078.5 \mathrm{~K} \\
\mathrm{~m}=18.23 \mathrm{~kg} / \mathrm{s}\end{array}$ & $\begin{array}{l}\text { DPM: trap } \\
\text { Emissivity }=1\end{array}$ \\
\hline $\begin{array}{l}\text { Nozzles for secondary air } \\
\text { injection }\end{array}$ & Mass flow inlet & $\begin{array}{l}\mathrm{T}=298 \mathrm{~K} \\
\mathrm{~m}=2.97 \mathrm{~kg} / \mathrm{s}\end{array}$ & $\begin{array}{l}\text { DPM: reflect } \\
\text { Emissivity }=1\end{array}$ \\
\hline Freeboard outlet & Pressure outlet & Gauge pressure $=0$ & DPM: escape \\
\hline RDF entry ports & Wall & $\begin{array}{l}\mathrm{T}=298 \mathrm{~K} \\
\mathrm{~m}=0.833 \mathrm{~kg} / \mathrm{s}\end{array}$ & $\begin{array}{l}\text { DPM: fuel injection } \\
\text { Emissivity }=1\end{array}$ \\
\hline Freeboard walls & Wall & $\mathrm{T}=1175 \mathrm{~K}$ & $\begin{array}{l}\text { DPM: reflect } \\
\text { Emissivity }=0.75\end{array}$ \\
\hline Boiler tubes & Wall & $\mathrm{T}=600 \mathrm{~K}$ & $\begin{array}{l}\text { DPM: reflect } \\
\text { Emissivity }=0.5\end{array}$ \\
\hline
\end{tabular}




\subsection{Results and validation}

The big CPU demand has imposed the parallel processing using a network of UNIX workstations. The solution has met the physical convergence criteria in about 1600 iterations. The analysis of the results calls attention to the combustion process, the velocity and temperature field and the chemical species concentration. The final purpose is the validation of the freeboard model.

The history of each single RDF particle can be tracked in a qualitative and quantitative way: the trajectory has been displayed in the domain (fig. 5) by selecting the desired number of streams. Besides, the DPM report gives information about the average residence time of the fuel particles in the freeboard (i.e. 4 s) and the combustion efficiency. Volatiles are completely released and burnt in the gas phase and the char conversion, which is obtained through heterogeneous reaction with oxygen, is $100 \%$, in accordance with experimental data.

The velocity field shows that the gas velocity varies from zero to $30 \mathrm{~m} / \mathrm{s}$; the maximum value occurs at the secondary air injection through the nozzles. The velocity contours are shown in fig. 6 for four different planes:

- $\mathrm{z}=1.6 \mathrm{~m}$, at the top of the combustion chamber;

- $\mathrm{z}=8.4 \mathrm{~m}$ and $\mathrm{z}=9.4 \mathrm{~m}$, where the secondary air is injected into the freeboard;

- $\mathrm{z}=11.15 \mathrm{~m}$, where the RDF is thrown into the furnace.

The interaction between continuous and discrete phases is shown by fuel particles drag around them: as a result, the gas velocity increases from $1.5-3 \mathrm{~m} / \mathrm{s}$ to $16-18 \mathrm{~m} / \mathrm{s}$. It is important to notice the fluid dynamic interaction between the air flows injected through the two series of nozzles, on each freeboard side (fig. 7): the penetration of the freeboard by the air jet increases with the series of nozzles along the $\mathrm{z}$ axis. Near the outlet section the average velocity rises: the cross section reduces from $27.15 \mathrm{~m}^{2}$ to $9.48 \mathrm{~m}^{2}$ therefore the gas velocity increases to about $10 \mathrm{~m} / \mathrm{s}$.

In the freeboard, the coexistence of the combustion process and the heat transfer between the flue gas and the evaporative tubes makes the temperature field examination quite significant. The radiation transport assures a homogeneous temperature distribution along the $\mathrm{x}$ axis (fig. 8). The maximum temperature reaches $1550 \mathrm{~K}$ : this value is much lower than the peak flame temperature (i.e. $2070 \mathrm{~K}$ ) because of the excess air.

As far as the chemical species concentration is concerned, carbon dioxide and oxygen are taken into consideration. The contours of $\mathrm{CO}_{2}$ molar fraction (fig. 9) are considerably affected by the presence of the secondary air that supplies the necessary oxygen to combustion; the lower values (about 7\%) in the base of the freeboard are due to the flue gas coming from the bed. On the contrary, the $\mathrm{O}_{2}$ concentration (fig. 10) rapidly decreases where the greater fuel amount is burnt.

The results here shown needed to be validated by means of comparison between the predicted and the experimental data. The experimental data available in the freeboard are the following:

- the temperature in proximity to the secondary air injection and to the exit (each value is measured by three thermocouples); 
- the chemical species concentration at the outlet.

In addition, the plant monitoring system measures the steam flow rate produced in the heat recovery steam generator and the one at the turbine inlet. The difference between these values equals the steam flow rate generated in the furnace: this datum is necessary for the estimation of the heat removed by boiler tubes.
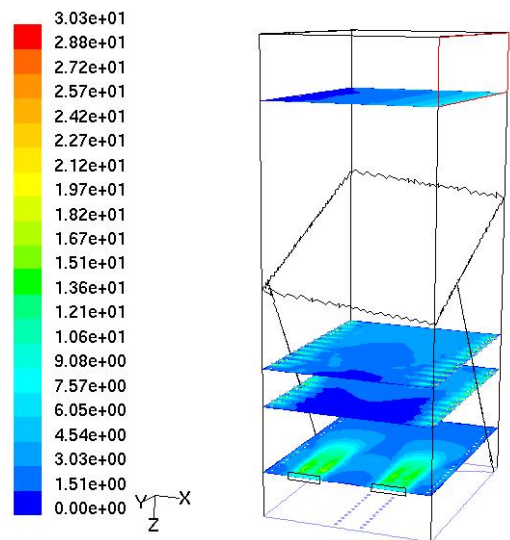

$\begin{array}{ll}\text { Figure 7: } & \begin{array}{l}\text { Velocity } \\ (\mathrm{m} / \mathrm{s}) \text { at } \mathrm{y}=2.964 \mathrm{~m} .\end{array}\end{array}$

$\begin{array}{ll}\text { Figure 7: } & \begin{array}{l}\text { Velocity magnitu } \\ (\mathrm{m} / \mathrm{s}) \text { at } \mathrm{y}=2.964 \mathrm{~m} .\end{array}\end{array}$
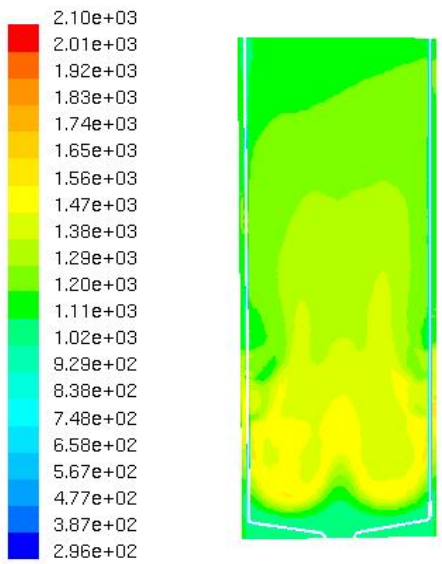

Figure 8: $\quad$ Static temperature (K) at $\mathrm{y}=2.5 \mathrm{~m}$. $\mathrm{at}=1.6 \mathrm{~m}, \mathrm{z}=8.4 \mathrm{~m}$ $=9.4 \mathrm{~m}$ and $\mathrm{z}=11.15 \mathrm{~m}$.
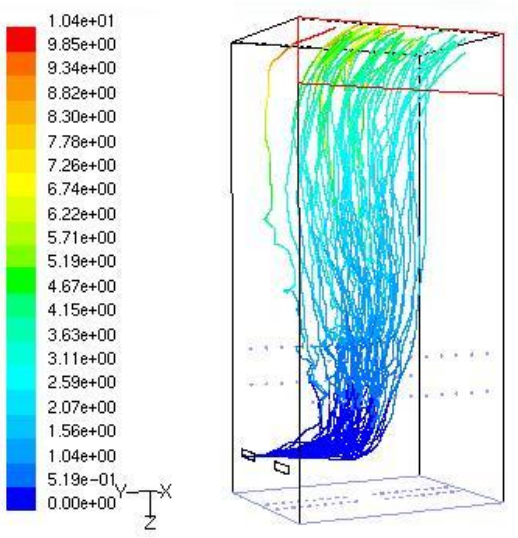

Figure 5:
RDF particles traces coloured by particle residence time (s).
$3.03 e+01$

$2.88 \mathrm{e}+01$

$2.72 \mathrm{e}+01$

$2.57 e+01$

$2.42 \mathrm{e}+01$

$2.27 e+01$

$2.12 \mathrm{e}+01$

$1.97 \mathrm{e}+01$

$1.82 \mathrm{e}+01$

$1.67 \mathrm{e}+01$

$1.51 e+01$

$1.36 \mathrm{e}+01$

$1.21 e+01$

$1.06 \mathrm{e}+01$

$9.08 \mathrm{e}+00$

$7.57 e+00$

$6.05 \mathrm{e}+00$

$4.54 \mathrm{e}+00$

$3.03 \mathrm{e}+00$

$1.51 e+00$

$0.00 \mathrm{e}+00$

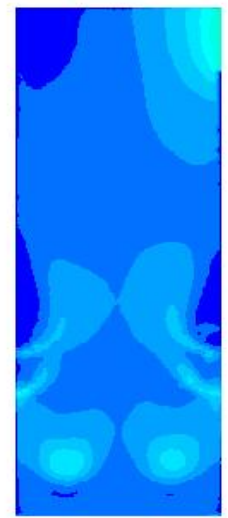

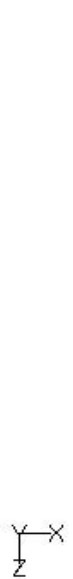

Figure 6: 
The differences of the computed data with respect to the experimental values are shown in the fourth column of table 4. It can be observed that, in general, there is a good agreement: the largest error $(6.7 \%)$ is on the $\mathrm{O}_{2}$ concentration. The model overestimates the heat transfer to the steam of about $4-5 \%$ mainly because the P1 model tends to overvalue the radiative fluxes from localized heat source. Consequently, the temperature of the gases leaving the freeboard is slightly undervalued. Nevertheless these differences, it can be concluded that the accuracy of the model predictions is more than satisfactory, because one has to take into account the big complexity of the physical process taking place in a real furnace and modelled by the computation. As regards the velocity field, no measured data are available for comparison; anyway, the prediction seems reasonable.
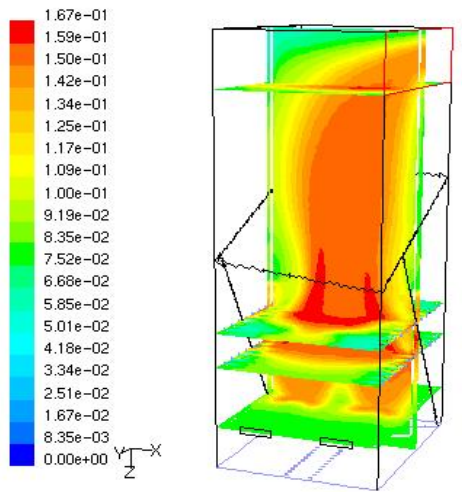

Figure 9: $\mathrm{CO}_{2}$ mole fraction at $\mathrm{z}=.6 \mathrm{~m}, \mathrm{z}=8.4 \mathrm{~m}$, $\mathrm{z}=.4 \mathrm{~m}, \mathrm{z}=11.15 \mathrm{~m}$ and $\mathrm{y}=2.5 \mathrm{~m}$.
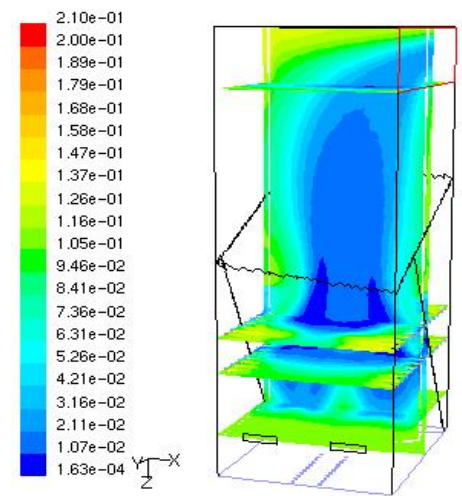

Figure 10: $\mathrm{O}_{2}$ mole fraction at $\mathrm{z}=1.6 \mathrm{~m}, \mathrm{z}=8.4 \mathrm{~m}$, $\mathrm{z}=9.4 \mathrm{~m}, \mathrm{z}=11.15 \mathrm{~m}$ and $\mathrm{y}=2.5 \mathrm{~m}$.

Table 4: Comparison between model outputs and experimental data.

\begin{tabular}{|l|c|c|c|}
\hline Variable & Model output & Experimental data & $\Delta \%$ \\
\hline Flue gas temperature $(\mathrm{K})$ at the freeboard outlet & 1176.4 & 1239.5 & $-5 \%$ \\
\hline Flue gas temperature $(\mathrm{K})$ at $\mathrm{z}=8.4 \mathrm{~m}$ & 1220 & 1218 & $+0.16 \%$ \\
\hline Gas-boiler tubes heat exchange $(\mathrm{kW})$ & 8065 & 7718 & $+4.3 \%$ \\
\hline Species molar fraction at the freeboard outlet: & & & \\
$\mathrm{C}(\mathrm{S})$ & $2.4 \mathrm{e}-5$ & - & \\
$\mathrm{CO}$ & $4.23 \mathrm{e}-7$ & - & \\
$\mathrm{CO}_{2}$ & 0.110 & 0.112 & $-1.8 \%$ \\
$\mathrm{H}_{2} \mathrm{O}$ & 0.084 & 0.086 & $-2.3 \%$ \\
$\mathrm{O}_{2}$ & 0.074 & 0.069 & $+6.7 \%$ \\
$\mathrm{~N}_{2}$ & 0.732 & 0.733 & $-0.1 \%$ \\
\hline
\end{tabular}




\section{Conclusions}

In theory, a FBC has a number of highly useful properties such as low combustion temperature, absence of temperature gradients in the bed, high combustion efficiency and easy pollutants reduction. In practice, BAS-ASM experience has shown that it is difficult to get a regular operation of a FBC fed by RDF, because of the high variability of the fuel heat content, the combustive air constraints imposed by bed fluidisation and the slag clustering. It followed that the combustor behaviour had to be analysed in depth and CFD modelling was regarded as the best way to pursue this aim.

At the moment, the development of the numerical techniques can't stand up to the multi-dimensional modelling of reactive fluidized beds so CFD analysis was restricted to the freeboard. The $3 \mathrm{D}$ freeboard modelling presented here has shown to include all the physico-chemical phenomena of main importance in solid fuels combustion processes: turbulence coupled with infinite rate chemistry, radiation and RDF reaction schemes are taken into account. The results have been compared with the experimental data: as the differences have been found in the range $4 \% \div 6 \%$, it can be concluded that the accuracy of the computed results is satisfactory. The high complexity of this case has seriously tested the numerical method: the reliability of the simulation outputs has proved that CFD is a valid instrument to analyse, retrofit and optimise the performance of a full scale industrial furnace fed by a non conventional fuel.

\section{References}

[1] Sriramulu, S., Sane, S., Agarwal, P. \& Mathews, T., Mathematical modelling of fluidized bed combustion. Fuel, 75, pp. 1351-1362, 1996.

[2] Marias, F., Puiggali, J. R. \& Flamant, G., Modeling for simulation of fluidized-bed incineration process. AIChE Journal, 47, pp. 1438-1460, 2001.

[3] Scala, F. \& Salatino, P., Modelling fluidized bed combustion of highvolatile solid fuels. Chemical Engineering Science, 57, pp. 1175-1196, 2002.

[4] Stopford, P. J., Recent applications of CFD modelling in the power generation and combustion industries. Applied Mathematical Modelling, 26, pp. 351-374, 2002.

[5] Eastwick, C. N., Pickering, S. J. \& Aroussi, A., Comparisons of two commercial computational fluid dynamics codes in modelling pulverised coal combustion for a 2.5 MW burner. Applied Mathematical Modelling, 23, pp. 437-446, 1999.

[6] Eaton, A. M., Smoot, L. D., Hill, S. C. \& Eatough C. N., Components, formulations, solutions, evaluation, and application of comprehensive combustion models. Progress in Energy and Combustion Science, 25, pp. 387-436, 1999.

[7] FLUENT user's guide, vols. 1-4, Lebanon, 2000.

[8] Boiko, E. A. \& Pachkovskii S. V., A kinetic model of thermochemical transformation of solid organic fuels. Russian Journal of Applied Chemistry, 77, pp. 1547-1555, 2004. 